2015-01

\title{
Evaluating shoreline identification using optical satellite images
}

Garcia-Rubio, G

http://hdl.handle.net/10026.1/3426

10.1016/j.margeo.2014.11.002

Marine Geology

Elsevier BV

All content in PEARL is protected by copyright law. Author manuscripts are made available in accordance with publisher policies. Please cite only the published version using the details provided on the item record or document. In the absence of an open licence (e.g. Creative Commons), permissions for further reuse of content should be sought from the publisher or author. 


\section{Highlights}

- A new method is proposed to assess shoreline change using optical satellite images.

- The method was validated using quasi-simultaneous shoreline measurements

- The validation revealed that satellite-derived shoreline is consistently seaward to the in situ shoreline.

- Consideration of water levels, beach slope and wave run-up is essential to determine confidence bounds of the satellite-derived shoreline.

- The method is shown to be successful and it could be applied to other locations. 


\title{
Evaluating shoreline identification using optical satellite images
}

\author{
Gabriela García-Rubio ${ }^{\mathrm{a}}$, David Huntley ${ }^{\mathrm{b}}$, Paul Russell ${ }^{\mathrm{b}}$ \\ ${ }^{a}$ CICESE, Physical Oceanography Department, Motorway Ensenada-Tijuana 3918, Playitas, \\ Ensenada, B.C., c.p. 22860, México. \\ ${ }^{b}$ Marine Institute and School of Marine Science and Engineering, Plymouth University, PL48AA, \\ United Kingdom.
}

\begin{abstract}
A technique to extract the shoreline location from optical satellite images has been developed and evaluated for the case study site of Progreso, Yucatán, México. A novel method to extract a satellite-derived shoreline (SDS) was developed ensuring the maximum contrast between sea and land. The area under investigation is an 8km length of shoreline that faces north into the Gulf of México.

The SDS was validated using quasi-simultaneous in situ shoreline measurements, both adjusted to equal water levels. In situ shoreline measurements recorded the instantaneous shorewards extent of the wave run-up when walking along the beach.

The validation of SDS revealed that the SDS is located consistently seawards of the in situ shoreline, explained by: a) the water depth that optical satellite image requires to identify a pixel either as sea or land, and b) the shorewards extent of the wave run-up. The overall distance between SDS and in situ shoreline is $5.6 \mathrm{~m}$ on average with a standard deviation of $1.37 \mathrm{~m}$ (in the horizontal) over $8 \mathrm{~km}$ of shoreline. Confidence bounds considering the shorewards extent of the wave run-up, inter-tidal
\end{abstract}

Email addresses: gabgarciarubio@gmail.com (Gabriela García-Rubio), D.Huntley@plymouth.ac.uk (David Huntley), P.Russell@plymouth.ac.uk (Paul Russell) 
beach slope variation and tidal uncertainty were computed to assess the accuracy of the SDS.

The SDS has been shown to be capable of detecting shoreline changes of less than $10 \mathrm{~m}$ and abrupt changes due to storms. The success of our method suggests that it should be applicable to other locations, after adapting the confidence bounds to the beach conditions.

Keywords: coastal monitoring, shoreline, coastal dynamics, remote sensing

\section{Introduction}

Shorelines are inherently dynamic features that mark the transition between land and sea and are vulnerable to waves, winds, nearshore currents, and human modification. It is estimated that there are more than $347,984 \mathrm{~km}$ of shoreline in the world and that $60 \%$ of the world's population lives within $100 \mathrm{~km}$ of the sea (Vitousek et al., 1997). Monitoring and managing shorelines is therefore of considerable social and economic importance. Furthermore shoreline erosion and coastal flooding were highlighted among the gravest effects of climate change (IPCC, 1990).

Monitoring the shoreline over appropriate time and spatial scales is challenging because shoreline change assessment involves consideration of the inherent dynamics of the shoreline over a range of temporal scales (Pajak and Leatherman, 2002; Gens, 2010). Although various types of data have been considered for shoreline change studies (Miller and Fletcher, 2003; Kumar and Jayappa, 2009; Chen and Chang, 2009), including maps, in situ beach profiling, LIDAR surveys and aerial photography, these techniques are inherently limited in temporal coverage, typically being either too short to identify long term trends or too widely spaced in time to distinguish short term, seasonal changes. 
Optical satellite imagery, on the other hand, has the potential to combine moderate spatial resolution with large spatial coverage and regular, short-timescale repeat measurement. It also has the potential advantage of allowing exploration of shoreline change in remote places with little coastal information. Satellite imagery has developed rapidly over the past few decades in terms of spatial resolution, frequency of passage over the same location and overall availability. For example, over the last 20 years, spatial resolution has improved from $10 \mathrm{~m}$ to $0.4 \mathrm{~m}$. An instantaneous visual image that covers a footprint of at least $220 \mathrm{~km}^{2}$ can now be obtained as often as once every 1 to 8 days.

Previous studies have investigated the potential of optical satellite images to study shoreline change (Blodget et al., 1991; Mason et al., 1997; White and El-Asmar, 1999; Aarninkhof, 2003; Foody et al., 2003; Kingston, 2003; Liu and Jezek, 2004; Zakariya et al., 2006; Ekercin, 2007; Dinesh-Kumar et al., 2007; Plant et al., 2007; Chen and Chang, 2009; Wang et al., 2010; Kuleli et al., 2011). However, none of these studies has fully assessed the accuracy of the derived shorelines through comparison with simultaneous and independent in situ observations.

The research described in this paper has three main objectives. The first is to develop a systematic, objective method to identify the shoreline from optical satellite images. The second is to validate the satellite-derived shoreline against in situ measurements made as close in time as possible to the satellite image. From this validation, the third aim is to assess bias and confidence bounds for the satellitederived shoreline locations, considering potential errors in the extraction method and environmental characteristics such as wave set-up and run-up, uncertainty in tide elevation, surge level and variations in beach slope. The overall aim is to provide a clear, quantitative and objective method for extracting shoreline location from satellite images which can be applied to a wide range of beach locations. 
The next section describes the study area chosen to evaluate satellite derived shorelines (SDS). Section 3 then sets out the newly developed method to extract SDS from satellite images. The results of applying the new method to images from the chosen study area are then described in section 4, which includes an assessment of the accuracy of the new method by estimating quantitative confidence bounds for the computed SDS. Finally the implications of our results are discussed in section 5, looking particularly at what would be needed to apply our method to other locations.

\section{Regional setting}

The chosen study area is located at Progreso, Yucatán, covering approximately $8 \mathrm{~km}$ of shoreline (Figure 1, Table 2). Most of the Yucatán shoreline has erosion problems and is sparsely populated. Due to its location, between the Gulf of México and the Caribbean Sea, the wave climate incident on Yucatán is fetch-limited but also experiences hurricanes every year. The continental shelf is wide and shallow with slopes of order 1:1000. Unfortunately the closest wave buoy (no. 42001) is $200 \mathrm{~km}$ offshore from Progreso at a depth of $3,365 \mathrm{~m}$. The wide continental shelf means that the observed wave height in deep waters $(0.5<\mathrm{Hs}>2 \mathrm{~m})$ is significantly different from shallow water $(<0.4 \mathrm{~m})$. The approaching waves into Progreso are locally generated by the wind with no presence of swell. Wave periods are small $(\mathrm{T}<4 \mathrm{~s})$ and measured wave heights (Hs) typically smaller than $30 \mathrm{~cm}$ at $5 \mathrm{~m}$ depth (Mariño-Tapia, 2010).

The tide is diurnal, with a form factor (F) larger than 3, indicating that the diurnal constituents are more important than the semidiurnal constituents (Pugh, 2004). The tidal range is microtidal with a maximum range of $0.9 \mathrm{~m}$. This tidal range is large enough to significantly change the shoreline location. For example, the $0.9 \mathrm{~m}$ range would produce a horizontal excursion larger than $15 \mathrm{~m}$ on a 1:20 beach slope. 
Progreso has a lack of reliable tidal measurements, so measurements were carried out in the current project to compare with existing tidal predictions.

The eastern-most segments of the studied shoreline do not have coastal vegetation and their inter-tidal beach width is the narrowest, ranging between $25 \mathrm{~m}$ and $52 \mathrm{~m}$. In addition, the east segments have houses very close to the shore on the top of the dunes. The mean grain size of the beach sand suggests an alongshore gradient. Overall the largest grain size $(0.28$ to $0.84 \mathrm{~mm})$ is towards the east and the finest sand $(0.22$ to $0.26 \mathrm{~mm})$ towards the west. The eastern section also shows a gradient of sand with fine sand $(0.28 \mathrm{~mm})$ in segment 6 . The alongshore gradient of the grain size is in agreement with a predominantly westwards alongshore transport, and with the direction of typical incoming winds from the NE.

There is one large man-made structure. Progreso pier extends offshore for $6 \mathrm{~km}$, with a shore-parallel breakwater at its seaward end of approximately $2 \mathrm{~km}$ length (Figure 1). The first $2 \mathrm{~km}$ of the pier has arches, partially allowing for sediment transport, and the last $4 \mathrm{~km}$ are solid. There is also a second pier that is $285 \mathrm{~m}$ long, approximately $110 \mathrm{~m}$ west of Progreso pier. Although both piers are not completely solid structures their presence is likely to cause a decrease in the alongshore transport rate leading to updrift accretion and downdrift erosion.

Shoreline orientation also provides an indication of physical processes modifying the beach. Shoreline orientation was measured using as reference the overall shoreline orientation, that runs from the West to East line. Negative values are clockwise and vice versa. Segment 4 has a slightly negative shoreline orientation $\left(-2^{\circ}\right)$ at the eastern side of the longest pier and much larger $\left(27^{\circ}\right)$ positive orientation at the western side of the pier. That is contrary to the expected shoreline shape with a westward alongshore transport. This suggests that Progreso pier has a significant effect on the local hydrodynamics and beach morphodynamics. 
The impact of hurricanes in the region is a constant threat. There are on average 10 hurricane events in the Atlantic basin per year, from which two events have intensities of at least hurricane category 3, holding winds higher than $178 \mathrm{kmh}^{-1}$ (NHC, 2010). Hurricanes Isidore (in 2002) and Gilbert (in 1988) directly impacted Yucatán (approximately 45km east from Progreso) producing considerable damage. Hurricane Isidore reached its peak intensity in Yucatán, with measured winds of $129 \mathrm{kmh}^{-1}$ and atmospheric pressure of $934 \mathrm{mb}$ (NHC, 2002). The properties located next to the beach were totally destroyed. Isidore changed the beach morphology, opening inlets connecting the coastal lagoon with the sea and so far, no recovery of the beach has been detected.

\section{Methods}

\subsection{Preliminary analysis of the optical satellite images}

Two cloud-free multispectral images (SPOT) from July $12^{\text {th }} 2010$ and September $9^{\text {th }} 2008$, both $10 \mathrm{~m}$ pixel size and a pre-processing level $2 \mathrm{~A}^{1}$, were obtained for the current study. Table 1 details the electromagnetic range covered by the spectral bands of the SPOT satellite.

Spectral bands from SPOT images cover most of the visible light and short wave infrared wavelengths (Table 1). Each surface on Earth has its unique response at each wavelength (Parker and Wolff, 1965), so the use of different spectral bands allows identification of specific features on the ground, such as the sea and the land.

In the first step in the analysis, the images were geometrically corrected to ensure positional accuracy within the pixel size. Once the images were geometrically

\footnotetext{
${ }^{1}$ Images with a pre-processing level $2 \mathrm{~A}$ are rectified to match a standard map projection (UTM WGS84), without using ground control points.
} 
corrected, the new method was developed and applied to extract SDS.

\subsubsection{Geometric correction of satellite images}

The geometric correction was performed using 45 in situ Ground Control Points (GCP). The chosen GCP were street intersections that were located all over the image, and the correction used a linear model involving translation of coordinates. The resulting root mean square error between the corrected image and the GCP was smaller than half the pixel size, as White and El-Asmar (1999) suggests. Detailed visual inspection was carried out ensuring that both images match the GCP.

\subsection{New method for extracting SDS from optical satellite images}

For shoreline change studies, it is necessary to identify the shoreline as a line that runs between pixels grouped as either sea or land. To achieve this, two major processes were required. First, a series of steps were followed to obtain a vector that represents the shoreline within the accuracy of the pixel size. Second, the location of the resulting vector has to be adjusted to a standard water level, correcting for the tidal level, meteorological conditions, wave height and inter-tidal beach slope, for the conditions when the satellite passed over Progreso.

\subsubsection{Identification of sea and land}

To identify pixels as sea and land different techniques were reviewed (filters, classification, visual interpretation), as well as the parameters (spectral band(s), convergence threshold and subsamples of the image) to use in the classification technique. Following the assessment of a number of options, the chosen technique was an unsupervised classification (ISODATA), executed in ERDAS software. The unsupervised classification has been used in previous research, for example by Foody et al. (2005), and allows the clearest definition of the sea and the land. The basic premise in the 
unsupervised classification is that the pixels within a group should have intensities with a similar spectral pattern. Conversely, intensities from a different group should be relatively well separated (Lillesand et al., 2008). In our case, we require the intensity values from the sea to have very similar spectral patterns and to have contrasting intensity values from those from the land.

Figure 2 (a) shows the cross-shore profile of pixel intensities along a representative cross-shore line from the analysed image. These intensity values reveal a clear drop in intensity values from land to sea for all the spectral bands. The intensities over the sea are relatively homogeneous.

Each spectral band and combinations of bands were assessed to find the optimum method for separating sea and land. As figure 2 (a) shows, the green band has relatively small differences in intensities from sea to land and their use resulted in some misclassification. The seawards drop in intensity is largest at the longer wavelengths (NIR and SWIR) and the optimum method was found to involve solely the NIR spectral band, with a convergence threshold for the objective classification of $95 \%$. No advantage was found when using subsamples or masks to focus on the area being classified so these were not used in the final method.

Figure 2 (b) shows the intensities of all the pixels in the image grouped as sea and land using the longer wavelengths (NIR and SWIR). The red points represent land and the blue points sea, based on an unsupervised classification using the NIR band. Intensities of pixels over the sea are the smallest $(<96)$ in the NIR, whilst the sea intensities in the SWIR spectral band range between 25 and 190 .

Visual verification of the geographic location of pixels in the overlap region, with similar intensities for the sea and the land was undertaken to ensure the correct identification of pixels as sea or land, and it was found that their spatial locations were far from the shoreline. These pixels correspond to streets and vegetation, which 
have both high and low intensities, as do the land and the sea. Therefore, although misclassification of these pixels could occur, their geographic location is far from the boundary between sea and land.

Figure 3 shows the extract of a classified image. The pixels in the sea region are identified as homogeneous and are well separated group from the pixels in the land region. It is important to emphasize that despite the fact that this region has very shallow water features, such as a coastal lagoon and inlets, the classification separates both groups well.

\subsubsection{Vectorisation of the classified image}

Vectorisation has the aim of obtaining a vector that represents the pixel boundary of the identified sea and land. The raster to vector conversion was executed in ArcMap software using standard conversion tools. The output is a stepped raw vector that goes along all the boundaries of the pixels in between the two groups in the analysed image (Figure 3). The vector has a pair of coordinates at each transition (Figure 4). Straight sections of the stepped raw vector do not have a pair of coordinates until a transition in the shore occurs.

\subsubsection{Smoothing}

The central locations of the pixels vary from image to image, so comparison between different stepped vectors would result in high frequency "noise". It is therefore prudent to smooth the stepped vectors to remove most of this noise.

The smoothing method chosen uses as input the stepped raw vector, locating the shoreline as the midpoint of each step. In straight sections without transitions, a pair of coordinates was added at $50 \mathrm{~m}$ intervals (Figure 4). These coordinates were then smoothed over a fixed alongshore distance. 
In order to assess the effect of the smoothing, the smoothed shoreline was compared with the in situ shoreline described below in section 3.3. Figure 5 shows the comparison of four different alongshore smoothing distances. The smoothed SDS at alongshore distances of $10 \mathrm{~m}$ and $20 \mathrm{~m}$ retain a jagged shape showing abrupt changes in the cross-shore ranging between -10 and $-1 \mathrm{~m}$, whereas smoothed SDS with a distance of 50 and $60 \mathrm{~m}$ range between -10 and $-4 \mathrm{~m}$, reducing the variation in the cross-shore by almost half the magnitude. The negative value indicates that the SDS is seaward of the in situ shoreline (see section 4.1).

The smoothed SDS at $50 \mathrm{~m}$ has been preferred because it removes shorter variations, captures well the shoreline shape and has the narrowest cross-shore variation. The chosen smoothed distance was found to be adequate for a location such as Progreso, where the shoreline orientation is mainly straight and does not show large, short-wavelength oscillations. The few oscillations in shoreline orientation (for example in segments 3 and 4) are well registered by the SDS (Figures 4 and 5).

\subsubsection{Water level considerations}

The instantaneous shoreline location measured by a satellite depends on tidal level and on wave run-up produced by the waves approaching the beach. To estimate their influence on the horizontal shoreline position, it is also necessary to know the intertidal beach slope.

Because local measurements at Progreso showed inconsistencies, new water level measurements were collected using a data logger RBR model TWR-2050, recording total pressure every 10 mins between July $12^{\text {th }}$ and August $4^{\text {th }} 2010$. Beach profiles were also surveyed on July $13^{\text {th }} 2010$ for each beach segment. The SDS was adjusted to a predetermined common tidal datum, in this case the local BMI (mean lower low water level, the acronym in Spanish is Bajamar Media Inferior). 
Satellite images cover a large area simultaneously, thus, the whole extracted shoreline has the same tidal level. However, the instantaneous shoreline location varies in the alongshore due to the wave run-up and set-up variation. The vertical wave runup in Progreso is typically between 0.2 and $0.4 \mathrm{~m}$ height. On a beach with a slope of $6^{\circ}$, that magnitude will cause a cross-shore excursion of between $2 \mathrm{~m}$ and $4 \mathrm{~m}$. The alongshore smoothing will also reduce the influence of run-up, tending to the smaller set-up values but dependent on the long-crestedness of the incident waves. For Progreso, the influence of waves is therefore considerably smaller than the pixel size. However, when comparing point locations of different smoothed shorelines, the magnitude could become significant, making it a potentially important limitation for shoreline change estimates. On shorelines with larger incident waves, it could become a dominant factor, as discussed below in section 4.2.2.

\subsection{Validation of the Satellite Derived Shoreline and ancillary data}

The SDS was validated by comparing the SDS from July $12^{\text {th }}$ with in situ shoreline measurements from the same day, with only five hours difference. The in situ shoreline measurements were adjusted to the tidal level when the satellite passed over Progreso (see section below). This inter-comparison is an excellent opportunity to examine the accuracy of the shoreline identification and so it has been used to define confidence bounds on the SDS.

The main difference between the SDS and the in situ shoreline measurements is the time span that occurred during in situ shoreline measurements. Both types of data registered the shoreward and the seaward extent of the wave run-up. However while the satellite captured an instantaneous picture of the shore, the in situ shoreline measurements captured a similar time-dependant feature when walking along the shore. 


\subsubsection{In situ shoreline measurements}

Because Progreso has such a small wave height $(<0.3 \mathrm{~m})$ it was possible to follow the instantaneous wave run-up and run-down. Measurements were carried out on July $12^{\text {th }}$ using a Leica Differential Global Positioning System (DGPS) in PostProcessing Kinematic (PPK) mode, recording positions every second. Each measurement is spaced approximately one and a half metres alongshore. An alongshore distance of $8 \mathrm{~km}$ was covered encompassing all the beach segments (Figure 1) and took two hours to complete.

The measurements were projected using a Universal Transverse Mercator (UTM) projection, zone $16 \mathrm{~N}$, with the geoid of reference WGS84. A planar projection adjusts effectively in flat places like Yucatán. The height measured during the in situ shoreline survey was verified with water levels measured in 2010 (see section 3.2.4) and tidal predictions. In this way it was possible to detect whether any other factors could be involved in the shoreline location apart from the tides (e.g. surges).

\subsection{Adjustment of the SDS and in situ shoreline measurement prior its inter-comparison}

Adjustment of in situ shoreline measurements ensures that the inter-comparison between SDS and in situ match on tidal levels. The first location surveyed (segment 8) showed a higher tidal level than the last location surveyed (segment 1). The approximate decrease in the tidal level was of approximately $40 \mathrm{~cm}$ height. In contrast, the SDS has the same tidal level at all points in the alongshore.

The adjustment was done using the inter-tidal beach slope and the difference in the predicted tidal level between the in situ measurements and the image. The adjustment to equal tidal levels was carried out under the assumption of a homogeneous inter-tidal beach slope for each beach segment. Because each beach segment was determined based on geomorphological characteristics, this assumption seemed to be 
adequate. However, it is recognised that local differences may occur particularly at the transitions between beach segments. For example the horizontal excursion of $20 \mathrm{~cm}$ difference in the water level on a beach slope of $3^{\circ}$ is $3.8 \mathrm{~m}$, whereas in a shallower beach of $1^{\circ}$ will have a horizontal excursion larger than $10 \mathrm{~m}$. The largest difference in beach slopes in the study area occurs from segment 1 to 2 , segment 3 to 4 and segment 4 to 5 (Table 1). Given these examples, the expected order of magnitude of discontinuity in the shoreline location to occur in the transitions between segments would be as large as $1.5 \mathrm{~m}$ from segment 1 to 2 , of $1 \mathrm{~m}$ from segment 3 to 4 and $0.6 \mathrm{~m}$ from segment 4 to 5 .

\section{Results}

\subsection{Validation of Satellite-Derived Shoreline}

4.1.1. Inter-comparison of the SDS and in situ shoreline measurements in July $12^{\text {th }}$ in 2010

The difference between the in situ shoreline measurements and the SDS using the new method was calculated for data gathered on $12^{\text {th }}$ July 2010. The comparison was based on measurements at every $10 \mathrm{~m}$ over $8 \mathrm{~km}$ of shoreline.

The results show that the SDS is consistently seawards of the in situ shoreline (Figures 6,7 ). On average over the $8 \mathrm{~km}$ length of shoreline, the SDS is $-5.6 \mathrm{~m}$ from the in situ shoreline, a value which is smaller than the pixel size $(10 \mathrm{~m})$ (Figure 6, Table 3).

Figure 7 also shows that eighty percent of the values are at a distance of one standard deviation from the average $(-6.9 \mathrm{~m}$ and $-4 \mathrm{~m})$, indicating a consistent seaward displacement of the SDS, though differences as large as the pixel size can occur at a few point locations $(0.2 \%)$. Table 3 shows the separate mean differences between the 
SDS and in situ for each beach segment. The magnitudes are in agreement with the overall magnitude and direction of the displacement. The mean of segment 4 is the only one that exhibits a larger displacement, which is probably due to the abrupt change in shoreline orientation.

The rapid variations about the mean displacement between the SDS and the in situ shoreline measurements are associated with fluctuations in the cross-shore extent of the wave run-up. The standard deviation of the DGPS height recorded during the in situ shoreline measurements ranges between $0.13 \mathrm{~m}$ and $0.38 \mathrm{~m}$, which also corresponds to the observed wave run-up in the region on the day of the measurements, which was between $0.2 \mathrm{~m}$ and $0.4 \mathrm{~m}$ height. The associated horizontal excursion for beach slopes between $3^{\circ}$ and $6^{\circ}$, as measured in Progreso, is between $1.7 \mathrm{~m}$ and $3.2 \mathrm{~m}$. That magnitude is approximately twice the horizontal standard deviation (Table 3), suggesting that the standard deviation is a good estimator of confidence bounds for the SDS.

\subsection{SDS confidence bounds}

The shoreline position captured by the satellite is instantaneous, but if different shorelines captured over a period of time are to be used to assess shoreline change, each SDS requires well defined confidence bounds. The current study enables us to make a tentative quantitative assessment of the factors that cause deviation of the SDS from the in situ shoreline and the uncertainty arising from adjusting shoreline position to a standard water level datum. This section summarises the uncertainties that arise from image rectification, beach slope variations, wave run-up and set-up, the offset due to absorption of light by sea water, tide levels and surge levels. 


\subsubsection{Image rectification}

The influence of image rectification is relatively simply to quantify. In the present case, use of 45 GCPs resulted in a standard deviation in the location of the pixels of less than $3 \mathrm{~m}$ for our rectified images (see section 3.1.1). This value is less than half the pixel size but is comparable with other sources of uncertainty.

\subsubsection{Beach slope}

Many of the factors involved in interpreting SDS require converting a vertical estimate of sea level variation into an associated horizontal variation using the beach slope. These factors include wave run-up, the minimum depth for identification of sea water, tide and surge levels. In the current study, beach slopes were measured in each of the eight beach segments and showed reasonable consistency across all segments (Table 2), the largest slope being in segment 4 and the smallest in segment 1. Nevertheless as discussed in section 3.3.2, uncertainty in the beach slope will result in an error in the SDS, particularly at the boundaries between the segments. The largest estimated error occurs at the boundary between segments 1 and 2 with a value of up to $1.5 \mathrm{~m}$ for a vertical tidal correction of $0.2 \mathrm{~m}$. Whilst this value is typically smaller than other uncertainties identified below, it does highlight the need for accurate intertidal beach slopes when applying the method, with the greatest sensitivity associated with the smallest beach slopes.

\subsubsection{Wave run-up}

As mentioned in the previous section, the magnitude of the cross-shore excursion of the wave run-up is a potentially important factor. The small standard deviation between the SDS and in situ shoreline in our study $(1.37 \mathrm{~m})$ is consistent with the small incident wave heights and measured beach slopes on the Progreso shoreline and is likely to be unimportant when comparing SDS from different times. This factor 
will of course become more important during larger wave events such as storms or hurricanes but it is unlikely that suitable satellite images would be available at such times. Nevertheless on beaches which experience larger incident waves, particularly swell, and with shallow beach slopes, the influence of wave run-up could be dominant.

\subsubsection{Seaward displacement of the SDS}

Error bounds on the observed seaward displacement of the SDS relative to the in situ shoreline are more difficult to quantify with confidence. The results described in section 4.1 show a mean seaward displacement over the $8 \mathrm{~km}$ studied of $5.57 \mathrm{~m}$ and it is encouraging that the values in the eight segments are well within one standard deviation of the overall mean, suggesting a degree of stability in this displacement for different beach slopes and wave exposure. The one exception is segment 4, but the presence of the pier and the rapid change of shoreline orientation in this segment probably accounts for the larger seaward displacement in this segment. However, the explanation of this displacement in terms of light absorption by sea water suggests that it might vary depending on water quality. At Progreso, the presence of fine sand means that turbidity is generally rather higher than might be expected from the small wave heights. The green and the red spectral bands do show evidence of these plumes of sediment in the nearshore water. The fact that the NIR band does not pick up these plumes suggests that their influence is minimal at the longer wavelengths, but conditions of higher turbidity, perhaps during slightly higher wave conditions, could increase the seaward displacement. The magnitude of any such effect is not known and needs further research.

\subsubsection{Tide level}

Another potentially significant contributor to error bounds for SDS is uncertainty in the instantaneous water level. Instantaneous water level is required in order to 
adjust SDS to a standard level before they are compared, so uncertainty in instantaneous level contributes directly to confidence bounds when comparing different SDS.

There are no reliable continuous measurements of water level at Progreso. Tidal level must therefore be based on tide predictions. Our own water level measurements over a three week period, described in section 3.2.4, show that the range of the predicted tide underestimates the real tidal range by $5 \%$. However, the microtides at Progreso (maximum range $0.9 \mathrm{~m}$ ) make this error unimportant when adjusting water levels for tidal differences, changing the horizontal location of the satellite typically by less than $1 \mathrm{~m}$.

\subsubsection{Surges}

Potentially much more important for shoreline location is the possible influence of surges in changing the water level. Some evidence of the influence of surges at Progreso was gained in an earlier comparison between SDS and in situ shoreline measured in September 2008 (García-Rubio et al., 2009). In 2008, the satellite image was obtained for $20^{\text {th }}$ September whilst the in situ measurements were carried out on $9^{\text {th }}$ September, during a period when Hurricane Ike was crossing the Gulf of México. Its nearest approach was approximately 500km away but the water levels measured during the in situ survey by the DGPS system showed the presence of a positive surge of around $30 \mathrm{~cm}$ at the start of the measurements, reducing almost to zero by the end of the survey. This progressive reduction of surge level added to the falling tide, resulting in a much larger drop of water level (Figure 8). This drop was also in good quantitative agreement with an observed trend in the cross-shore difference between the SDS and the in situ shoreline, with a difference of around $2 \mathrm{~m}$ based on the falling tide alone. Over a typical beach slope of around $3^{\circ}$ a surge 
of $30 \mathrm{~cm}$ would produce a horizontal displacement of the shoreline of around $5.7 \mathrm{~m}$. The frequency and magnitude of surges along the coast at Progreso is not known, but these observations suggest that their effect can be comparable with the tidal excursion. The conclusion proposed by García-Rubio et al. (2009) was that images obtained when a hurricane was in the vicinity should be avoided if possible.

\subsubsection{Overall confidence bounds}

The balance of each of the factors discussed in this section will depend on the conditions at any given location, but for Progreso, the primary factors contributing to error bounds on the SDS are found to be the image rectification, the wave run-up and a much smaller effect of uncertainty in the tidal level. Based on the observations from 2010, the combined influence of these factors gives an overall standard deviation of approximately $5 \mathrm{~m}$ when averaged over several kilometres of shoreline, which is smaller than the pixel size of $10 \mathrm{~m}$. As pointed out, however, there remains some unquantified uncertainty about the variability of the seaward offset of the SDS from the true shoreline and the influence of surges even when no hurricane is obviously nearby.

\subsection{Shoreline change measured using SDS and in situ shoreline measurements}

Shoreline change assessed over a two year-period (2008-2010) using in situ shoreline measurements is within the same range as the change measured using SDS (Figure 9). Segment 4 shows a change of $33 \mathrm{~m}$ and an abrupt change in shoreline orientation. The estimated shoreline change is within the estimated shoreline change using SDS, showing the capabilities of the SDS to identify shoreline change at shorelines with an abrupt change in shoreline orientation.

Shoreline change smaller than $5 \mathrm{~m}$ was detected using in situ shoreline measurements but were not detected by SDSs (e.g. segments 2, 7 and 8), showing that 
shoreline change assessment using SDSs cannot detect changes that occur below half the magnitude of the pixel size. Nevertheless SDSs can provide a very good estimation of the overall shoreline change. This is particularly valuable for those locations with no in situ shoreline measurements or few measurements of the shoreline position.

The measured in situ shoreline change is closer to the upper bound (landward) of the SDS confidence limits than the lower bound (seaward). This is likely to be due to an uncertainty in the water levels of the in situ shoreline measurements from 2008, and not to the capability of the SDS to detect shoreline change. However, the shoreline change assessed using in situ shoreline measurements remains within the defined range of shoreline change using SDS.

This comparison confirms that the use of SDS provides another resource to explore shoreline change covering large geographical scales $(>1 \mathrm{~km}$ and $<40 \mathrm{~km})$ and that its future application to assess longer periods of time is possible. This is the subject of future research.

\section{Discussion}

Systematic shoreline identification using optical satellite images has proved to be possible using the new method. The new method is based on the inherent physical properties of sea and land, which make the reflected energy from the NIR wavelengths have higher and lower intensities over the land and sea respectively. Estimation of the water levels (tide, wave run-up), beach slope, and the use of a common vertical tidal datum allowed high accuracy to be achieved in the shoreline identification.

The inter-comparisons between SDS and in situ shoreline measurements allowed validation of SDS and a better understanding of the factors involved in shoreline identification. Although there are a number of research projects that have previously used optical satellite images for shoreline identification (Blodget et al., 1991; White 
and El-Asmar, 1999; Mason et al., 1997; Aarninkhof, 2003; Liu and Jezek, 2004; Zakariya et al., 2006; Ekercin, 2007; Dinesh-Kumar et al., 2007; Chen and Chang, 2009; Wang et al., 2010; Kuleli et al., 2011; Foody et al., 2003), no validation has been carried out using quasi-simultaneous in situ shoreline measurements. Therefore these inter-comparisons are a first indication of the differences between a shoreline identified by optical satellite images in relation to in situ shoreline measurements.

The validation revealed that the extracted SDS at Progreso has a bias from in situ shoreline measurements of $-5.6 \mathrm{~m}$. This bias is probably related to the optical requirements of the NIR spectral band to detect a pixel as sea. This is in agreement with the research of Lafon et al. (2002) where the NIR significantly decreases intensity values with depth and with White and El-Asmar (1999) who used NIR to study shoreline change. Other factors such as depth variation, suspended particles in the water column, and probably the presence of small ripples on the sea surface would also affect the required minimum water depth for a pixel to be identified as sea. The change in intensity values due to the previously mentioned factors has not been fully explored in this research. However, the range of water depth estimated in this research is within the order of magnitude $(0.5 \mathrm{~m})$ that Lafon et al. (2002(a) determined when deriving bathymetry from optical satellite images at the Banc d'Arguin in France.

Tidal levels should be as precise as possible. The results of this research also show that uncertainties in water levels degrade the accuracy of shoreline location, even at locations with microtidal conditions. The implication of this is that satellite images alone cannot provide precise shoreline identification. The lack of water level and beach slope estimations for Progreso limits the accuracy of shoreline identification and hence shoreline change studies. Estimation of water levels and inter-tidal beach slope is essential for the further application of our method to other locations. 
The inter-comparisons showed that the deviation of SDS relates to the crossshore extent of the wave run-up. Wave run-up has not previously been considered in shoreline change studies using satellite optical images. Its acknowledgement can help to develop better evaluation of shoreline estimations. Wave run-up has been shown to be a major factor in limiting the accuracy of the SDS. At Progreso, this factor was one of the largest contributors to the confidence bounds on the SDS but was still well below the pixel size due to the low incident wave conditions.

When analysing large geographical areas the magnitude and the variation in the alongshore of the wave run-up could lead to large confidence bounds and therefore decrease our capability to detect the shoreline. Alongshore smoothing would average out most of the cross-shore extent of the wave run-up but would still leave the effect of wave set-up. Thus estimation of the wave set-up and wave run-up is required when assessing shoreline change and cannot be neglected when assessing the accuracy of SDS.

For other sites with large incident waves and low beach slopes, the wave run-up variations will be much larger and could severely limit the accuracy of the SDS. Wave run-up has been shown to be a major factor in limiting the accuracy of the SDS, but has not previously been considered in shoreline change studies using satellite optical images.

This factor could in principle be alleviated to some extent by alongshore averaging of the shoreline but its effectiveness would depend on the long-crestedness of the incident waves, itself variable, and wave set-up (a negligible factor at Progreso) would also contribute uncertainty. At Progreso, this factor was one of the largest contributors to the confidence bounds on the SDS but was still well below the pixel size due to the low incident wave conditions.

The application of SDS to explore shoreline change on different types of beaches 
requires a definition of confidence intervals. Confidence intervals can be based on in situ shoreline measurements or on accurate estimations of the shoreward extent of the wave run-up and the beach slope. Because these factors vary at different locations, the confidence bounds will increase for some beach types, reaching a magnitude at which shoreline change detection would not be possible in extreme cases. For example, beaches with large run-up and tidal range, without good measurements of incident wave height, and beaches with large uncertainty of actual water levels, either because tide predictions are poor or because of potentially large surge levels, would not be suitable for our new method.

A more serious factor for Progreso, and potentially for other sites, is the possible change in the mean water level due to a surge. The in situ measurements at Progreso in 2008 reveal a surge with a maximum height of $0.3 \mathrm{~m}$, diminishing over the time of the survey but displacing the shoreline by up to $6.5 \mathrm{~m}$. This value is larger than the uncertainty due to wave run-up and comparable with the effect of the tides. At Progreso, this surge was undoubtedly associated with the passage of Hurricane Ike a minimum of 500km away, and surges of this magnitude may not occur at times when there is no hurricane in the vicinity. However, in the absence of continuous water level measurements, this remains conjecture.

Combining the uncertainties for Progreso, based on the observed variability of the seaward displacement and assuming no surge for the 2010 observations, gives an estimated standard deviation for the SDS of about half the pixel size. However, it is interesting to note that most of the factors contributing to the standard deviation would not be reduced for an image with a smaller pixel size. The primary benefit of a smaller pixel size is likely to be the alongshore scale of features which can be observed, but for the larger scale features which generally contribute most to shoreline change, the pixel size of $10 \mathrm{~m}$ is probably adequate. 


\section{Conclusion}

A method has been developed to identify the shoreline from satellite optical images, applying an unsupervised classification, using the NIR spectral band (95\% convergence threshold and no mask) to separate the sea and the land. Adjustment of shoreline position considering water levels (tide and wave run-up) and beach slope has been shown to be essential.

The SDS identified with satellite optical images is located seawards with a mean cross-shore displacement of $-5.6 \mathrm{~m}$ and a standard deviation of $1.4 \mathrm{~m}$ over $8 \mathrm{~km}$ of shoreline. This difference was assessed using quasi-simultaneous in situ measurements, over a five hour period, both adjusted to equal tidal levels.

Confidence bounds for the SDS were defined including the horizontal excursion of the wave run-up, uncertainty on tidal levels and inter-tidal beach slope variability. The defined confidence bounds are within the pixel size and they are shown to be effective to explain the deviation of the SDS from in situ shoreline measurements.

Estimated shoreline change over a two year period with SDS is within the same magnitude as the estimated shoreline change using in situ shoreline measurements. The SDS measurements proved able to detect abrupt changes in the shoreline location, encouraging the further exploration of the technique to determine shoreline change over longer periods of time and larger extents of shoreline.

\section{References}

Aarninkhof, S., 2003. Nearshore bathymetry derived from video imagery. Ph.D. thesis, Delft University, Delft University of Technology, Netherlands.

Blodget, H. W., Taylor, P. T., Roark, J., 1991. Shoreline changes along the RosettaNile promontory monitoring with satellite observations. Marine Geology 99, 67-77. 
Chen, W., Chang, H.-K., 2009. Estimation of shoreline position and change from satellite images considering tidal variation. Estuarine, Coastal and Shelf Science $84,54-60$.

Dinesh-Kumar, P. K., Gopinath, G., Laluraj, C., Seralathan, P., Mitra, D., 2007. Change Detection Studies of Sagar Island, India, using Indian Remote Sensing Satellite 1c Linear Imaging Self-Scan Sensor III Data. Journal of Coastal Research 23 (6), 1498-1502.

Ekercin, S., 2007. Coastline Change Assessment at the Aegean Sea Coasts in Turkey Using Multitemporal Landsat Imagery. Journal of Coastal Research 23 (3), 691698.

Foody, G. M., Muslim, A. M., Atkinson, P. M., 2003. Super-resolution mapping of the shoreline through soft classification analyses. IEEE Transactions on Geoscience and Remote Sensing, 3429-3431.

Foody, G. M., Muslim, A. M., Atkinson, P. M., 2005. Super-resolution mapping of the waterline from remotely sensed data. International Journal of Remote Sensing $26(24), 5381-5392$.

García-Rubio, G., Huntley, D., Kingston, K., Esteves, L., September 2009. Shoreline identification using satellite images. In: Mizuguchi, M., Sato, S. (Eds.), Proceedings of Coastal Dynamics: Impacts of Human Activities on Dynamic Coastal Processes. No. 117. World Scientific, pp. 1-10.

Gens, R., 2010. Remote sensing of coastlines: detection,extraction and monitoring. International Journal of Remote Sensing 31, 1819 -1836. 
IPCC, 1990. "Policymaker's: Summary of the Potential Impacts of Climate Change" report from working group ii to the intergovernmental panel on climate change. Tech. rep., Intergovernmental Panel on Climate Change.

Kingston, K., 2003. Applications of complex adaptative systems, approaches to coastal systems. Ph.D. thesis, University of Plymouth, Plymouth.

Kuleli, T., Guneroglu, A., Karsli, F., Dihkan, M., 2011. Automatic detection of shoreline change on coastal wetlands of Turkey. Ocean Engineering 38, 1141-1149.

Kumar, A., Jayappa, K. S., 2009. Long and Short-term Shoreline Changes Along Mangalore Coast, India. Int. J. Environ. Res. 3 (2), 177-188.

Lafon, V., Dupuis, H., Howa, H., Froidefond, J., 2002. Determining ridge and runnel longshore migration rate using SPOT imagery. Oceanologica Acta 25, 149-158.

Lafon, V., Froidefond, J., Lahet, F., Castaing, P., 2002(a). SPOT shallow water bathymetry of a moderately turbid tidal inlet based on field measurments. Remote Sensing of Environment 81, 136-148.

Lillesand, T., Kiefer, R., Chipman, W., 2008. Remote Sensing and Image Interpretation, 6th Edition. John Wiley \& Sons, Inc., United States of America.

Liu, H., Jezek, K., 2004. Automated extraction of coastline from satellite imagery by integrating Canny edge detection and locally adaptive thresholding methods. International Journal of Remote Sensing 25 (5), 937-958.

Mariño-Tapia, I., 2010. pers.comm. CINVESTAV-Merida, Researcher from Oceanography Physics in CINVESTAV-Merida. 
Mason, D. C., Davenport, I., Flather, R., 1997. Interpolation of an Intertidal Digital Elevation Model from Heighted Shorelines: a Case Study in the Western Wash. Estuarine, Coastal and Shelf Science 45, 599-612.

Miller, T. L., Fletcher, C. H., 2003. Waikiki: Historical analysis of an engineered shoreline. Journal of Coastal Research 19 (4).

NHC, 2002. Hurricane Isidore. Tropical Cyclone Report. Tech. rep., National Huricane Center (NHC), http://www.nhc.noaa.gov/.

Pajak, M. J., Leatherman, S., 2002. The High Water Line as Shoreline Indicator. Journal of Coastal Research 18 (2), 329-337.

Parker, D. C., Wolff, M. F., 1965. Remote sensing. International Science and Technology 43, 20-31.

Plant, N., Aarnikhof, S., Turner, I., Kingston, K., 2007. The performance of shoreline detection models applied to video imagery. Journal of Coastal Research 23 (3), 658-670.

Pugh, D., 2004. Changing sea levels: Effects of tides, weather and climate. Cambridge University Press, Cambridge.

Vitousek, P. M., Mooney, H. A., Lubchenco, J., Melillo, J. M., 1997. Human Domination of Earth's Ecosystems. Science 277 (5325), 494-499.

Wang, C., Zhang, J., Ma, Y., 2010. Coastline interpretation from multispectral remote sensing images using an association rule algorithm. Int. J. Remote Sensing 31 (24), 6409-6423. 


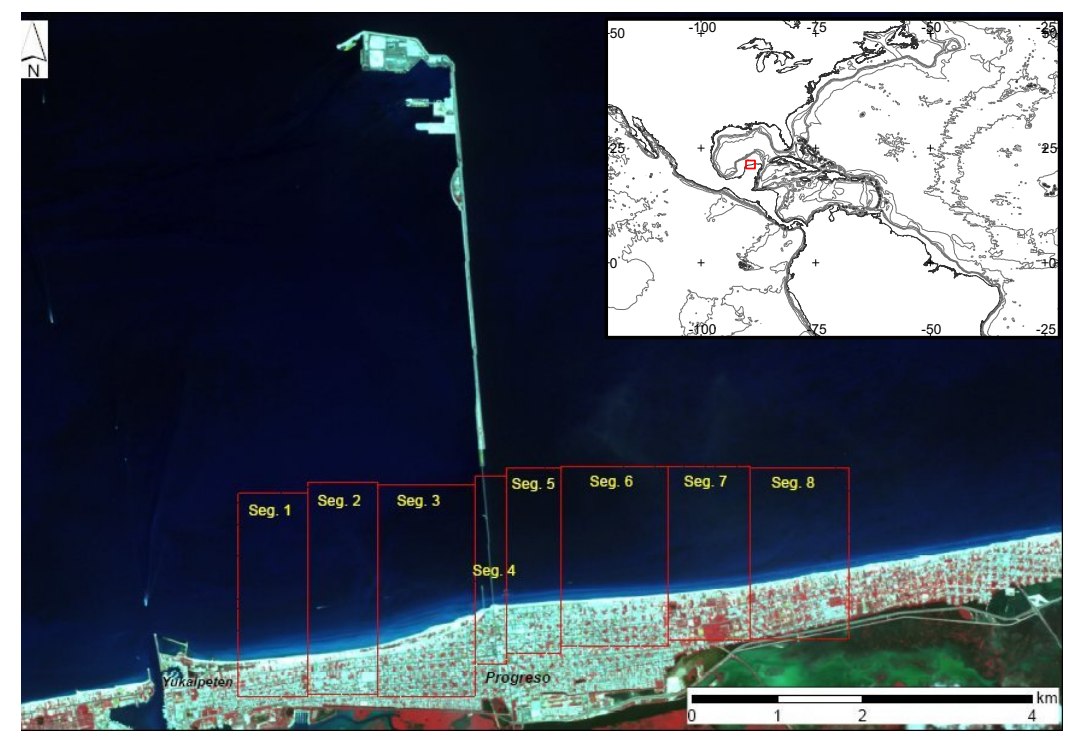

Figure 1: Geographic location of Progreso, Yucatán, México (upper box), and the studied shoreline segments.

White, K., El-Asmar, H. M., 1999. Monitoring changing position of coastlines using Thematic Mapper imagery, an example from the Nile Delta. Geomorphology 29, 93-105.

Zakariya, R., Rosnan, Y., Saidin, S., Yahaya, M., Kasawani, I., Lokman, H., 2006. Shoreline detection and changes for Terengganu River mouth from satellite imagery (LANDSAT 5 and LANDSAT 7). Journal of Sustainability Science and Management 1 (1), 47-57. 


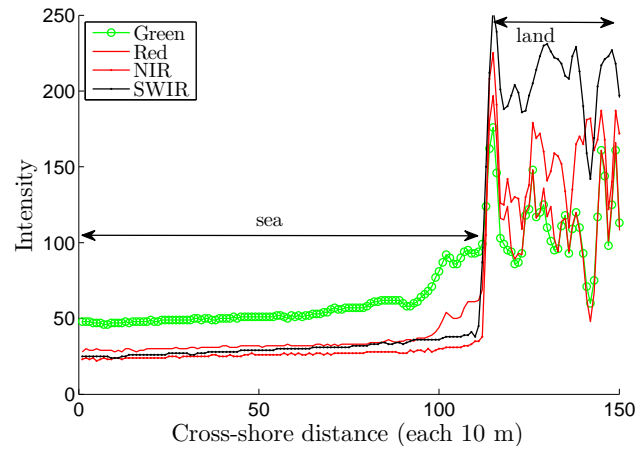

(a)

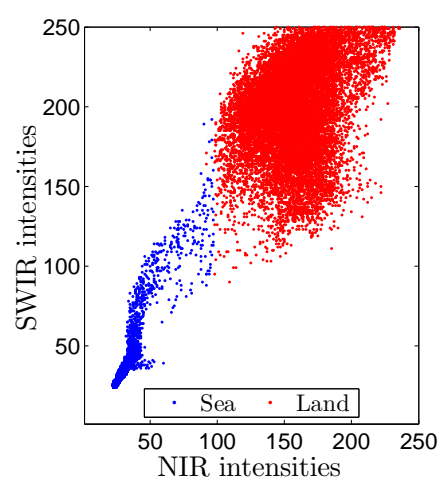

(b)

Figure 2: a) Cross-shore spectral profile in intensity values at a point location along the shoreline level. The horizontal axis is spaced by the pixel size $(10 \mathrm{~m})$. (b) Intensities from the NIR against the SWIR from the pixels identified either as sea and land covering the entire image.

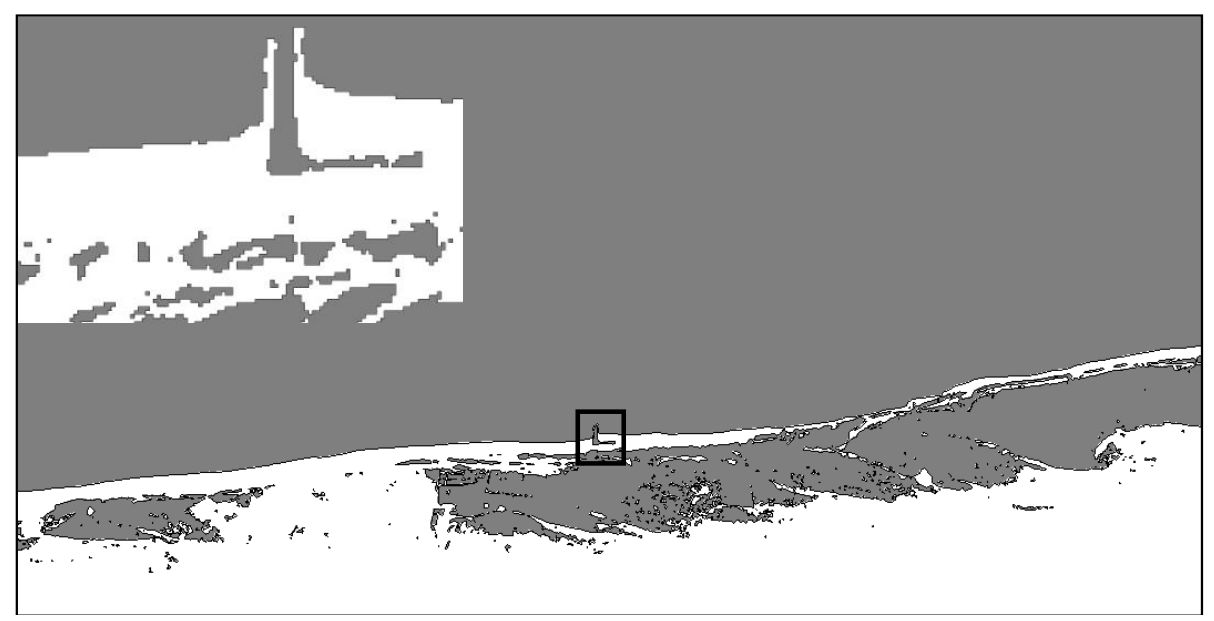

Figure 3: Extract of a classified image in sea (grey) and land (white) using the NIR spectral band. The close-up is the area within the black square. 


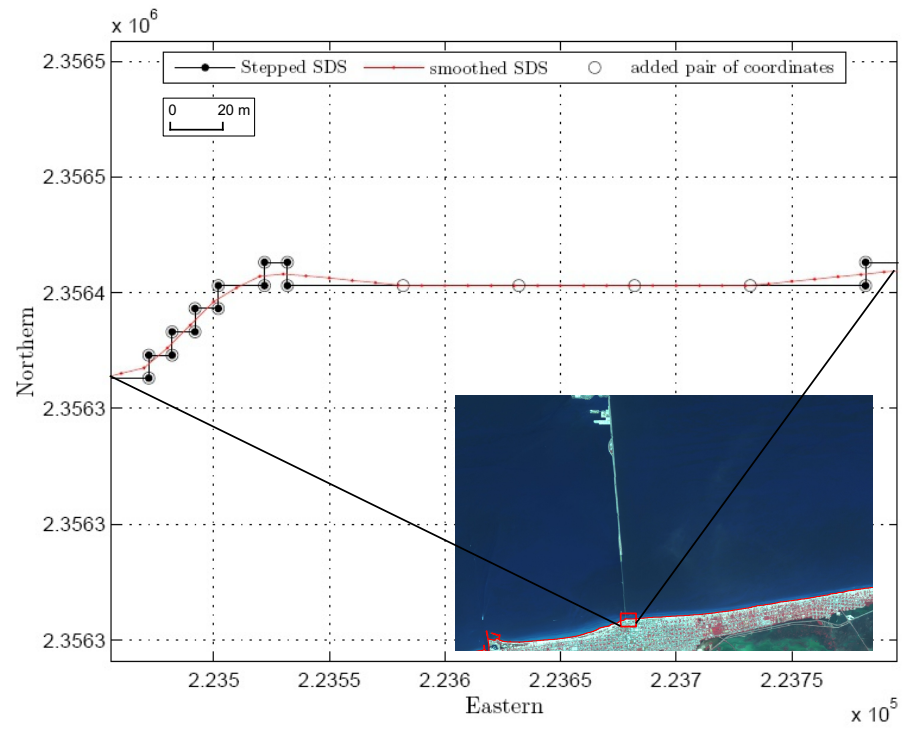

Figure 4: Smoothed vector (red line) using an alongshore distance of $50 \mathrm{~m}$, and stepped raw vector (black line) from the raster to vector conversion. The horizontal axis is the Eastern and the vertical axis is the Northern coordinates, projected using a UTM projection $16 \mathrm{~N}$. 


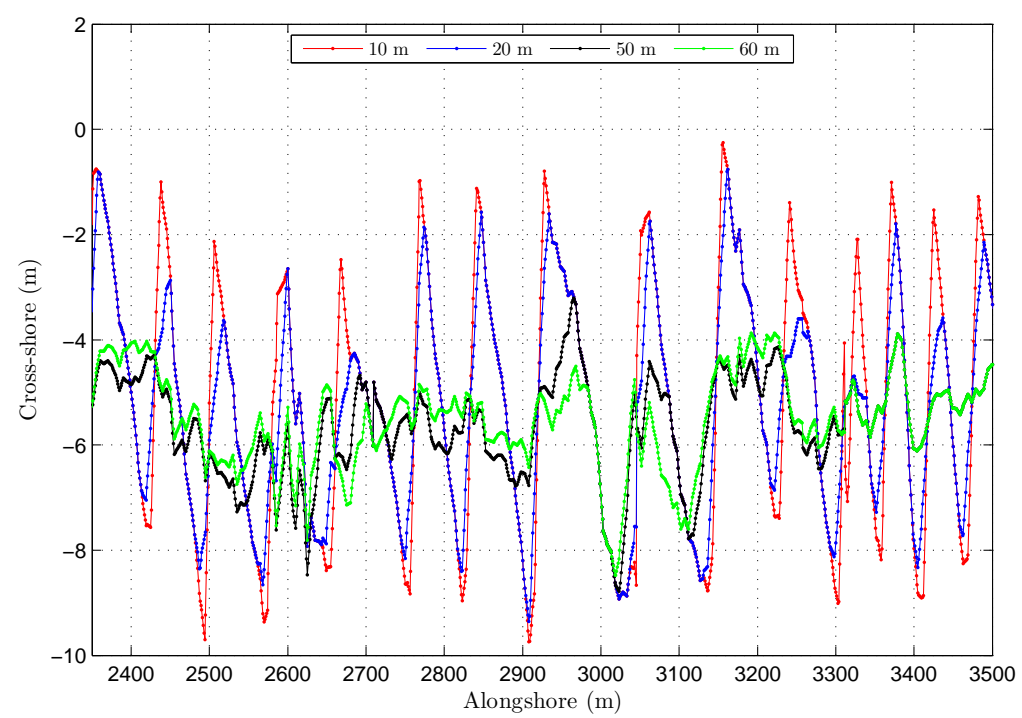

Figure 5: Smoothed SDS using different distances in the alongshore (10 (red), 20 (blue), 50 (black) and 60m (green)). 


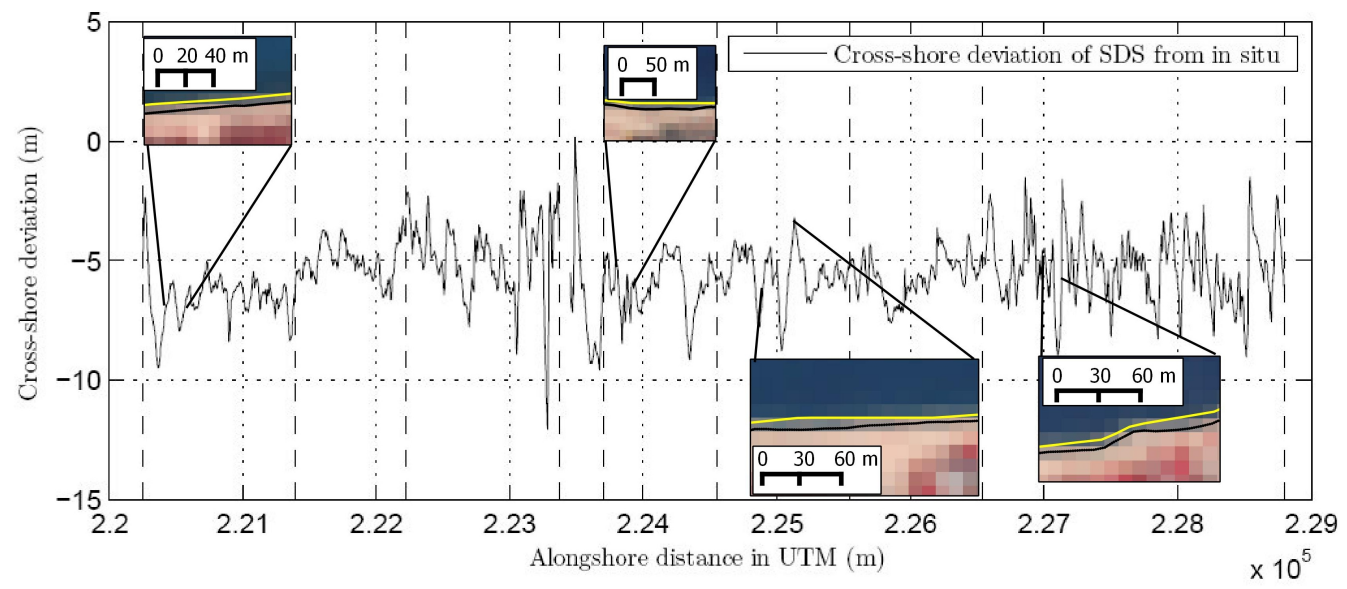

Figure 6: Difference in the cross-shore $(\mathrm{m})$ between the SDS and in situ shoreline measurements (2010) in Progreso, Yucatán. Horizontal axis is the eastern, vertical axis is the northern coordinates in a UTM projection (16 zone North). Segments 1 to 8 are from left to right (dashed lines). Progreso piers are located within segment 4 at $2.238 \mathrm{~m}$ eastern. 


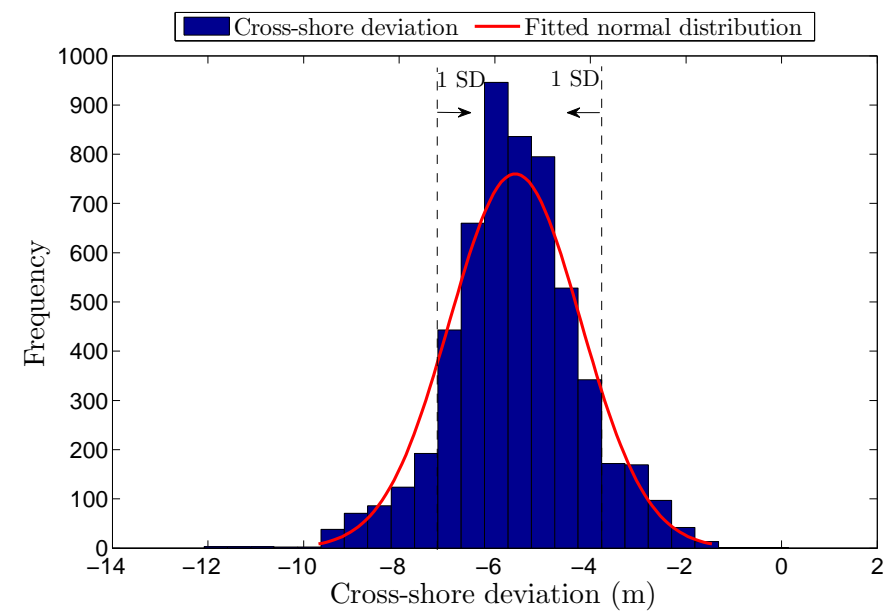

Figure 7: Histogram of the cross-shore distance between in situ shoreline measurements and SDS in 2010. The distribution fits into a normal distribution $(\mathrm{k}=0.979$, c.v. $=0.0182, \mathrm{n}=709)$. The dashed lines indicate the values within 1 standard deviation from the average. 


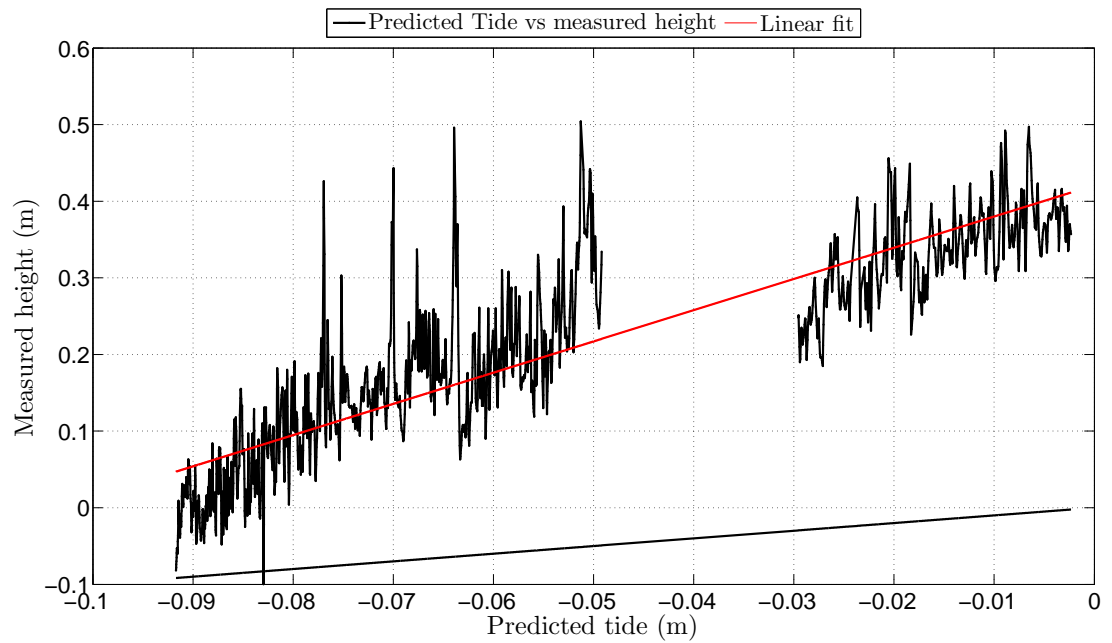

Figure 8: Measured height during the in situ shoreline measurements against the predicted tide (in relation to the local BMI) in 2008 at Progreso, Yucatán, México. The gradient is -4 , the intercept is $0.42 \mathrm{~m}$, and $\mathrm{r}^{2}=0.78$. The black line has a gradient of 1 placed as a reference. 
Table 1: Electromagnetic range covered by the spectral bands of SPOT satellite.

\begin{tabular}{|cccl|}
\hline Spot satellite & Spectral bands & Pixel size $(\mathrm{m})$ & Spectral resolutions \\
\hline 5 & Panchromatic & 2.5 or 5 & 0.48 to $0.71 \mu \mathrm{m}$ \\
Green & 10 & 0.50 to $0.59 \mu \mathrm{m}$ \\
Red & 10 & 0.61 to $0.68 \mu \mathrm{m}$ \\
Near infrared & 10 & 0.78 to $0.89 \mu \mathrm{m}$ \\
& Short-wave infrared & 10 & 1.58 to $1.75 \mu \mathrm{m}$ \\
\hline \multirow{2}{*}{4} & Monospectral & 10 & 0.61 to $0.68 \mu \mathrm{m}$ \\
& Green & 20 & 0.50 to $0.59 \mu \mathrm{m}$ \\
Red & 20 & 0.61 to $0.68 \mu \mathrm{m}$ \\
Near infrared & 20 & 0.78 to $0.89 \mu \mathrm{m}$ \\
Short-wave infrared & 20 & 1.58 to $1.75 \mu \mathrm{m}$ \\
\hline
\end{tabular}


Table 2: Beach characteristics of the beach segments from Progreso, the case study area, $\alpha$ is the shoreline orientation using as a reference the West to East line. Positive values are anticlockwise, and negative values are clockwise, $\beta$ is the beach slope in degrees.

\begin{tabular}{|ccccccccc|}
\hline & \multicolumn{4}{c}{ West } & \multicolumn{5}{c|}{ East } \\
\hline & Seg.1 & Seg.2 & Seg.3 & Seg.4 & Seg.5 & Seg.6 & Seg.7 & Seg.8 \\
\hline$\alpha\left(^{\circ}\right)$ & 5 & 8 & 18 & 27 to -2 & 3.1 & 3.7 & 6.8 & 9.7 \\
$\beta\left(^{\circ}\right)$ & 3 & 5 & 5 & 9 & 6 & 6 & 5 & 5 \\
Beach width $(\mathrm{m})$ & 80 & 50 & 178 & 15 & 30 & 52 & 25 & 23 \\
& & & & & & & & \\
$\bar{X}$ grain size $(\mathrm{mm})$ & 0.22 & 0.26 & 0.24 & 0.61 & 0.34 & 0.28 & 0.52 & 0.84 \\
Coastal vegetation & Yes & Yes & Yes & No & No & No & No & No \\
Coastal structures & No & No & No & Yes & No & No & No & No \\
Length $(m)$ & 810 & 810 & 1,300 & 310 & 680 & 1,185 & 1,000 & 2,280 \\
\hline
\end{tabular}

Table 3: Cross-shore difference (m) of the SDS and in situ in 2010.

\begin{tabular}{|lcccccccc|}
\hline & 2010 & \multicolumn{7}{c|}{ Mean=-5.57 m, SD=1.37 m } \\
\cline { 2 - 9 } & Seg. 1 & Seg. 2 & Seg. 3 & Seg. 4 & Seg. 5 & Seg. 6 & Seg. 7 & Seg. 8 \\
\hline Mean & -6.6 & -5 & -4.7 & -7.4 & -6 & -5.6 & -5.7 & -5.3 \\
Std. dev. & 1 & 0.8 & 1.6 & 1.9 & 1.1 & 1 & 0.9 & 1.4 \\
Range & 7.1 & 3.5 & 10.3 & 9.7 & 4.9 & 5.6 & 4 & 7.5 \\
\hline \hline
\end{tabular}




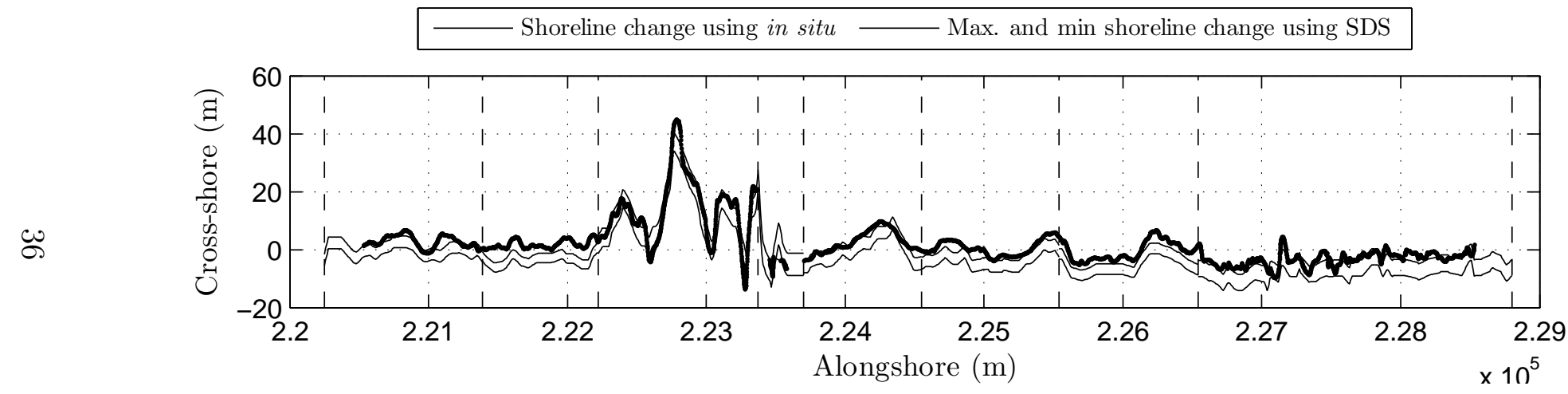

Figure 9: Shoreline change from September 2008 to July 2010 estimated using in situ shoreline measurements and SDS. 